\title{
BILATERAL FULMINATING ENDOPHTHALMITIS WITH STREPTOCOCCAL SEPTICAEMIA*
}

BY

\author{
C. B. WALKER AND P. FENWICK \\ St. Thomas's Hospital, London
}

ACUTE and irrecoverable blindness due to bilateral intra-ocular inflammation is fortunately rare in clinical practice.

The case to be described was noted for the catastrophic occurrence of such an inflammation, associated with a streptococcal septicaemia, and was of such severity as to suggest the existence of an ocular hypersensitivity to streptococci or their products.

\section{Case Report}

A married woman, aged 45, was admitted under the care of Mr. John Winstanley on October 26, 1960, with sudden blindness and fever.

History.-Normally a healthy person, she had experienced a sore throat and diarrhoea a fortnight before admission which cleared up quickly, to be followed a week later by rigors, headache, and thirst which necessitated a return to bed. This was soon followed by almost complete blindness and the occurrence of tender red patches on her elbow and foot. She was then admitted to hospital.

Family History. - At the outset her husband and two children had also suffered brief episodes of sickness and diarrhoea.

Examination.-Pulse 120 , temperature $103.0^{\circ} \mathrm{F}$., respiration 22 . She appeared toxic, but was rational and co-operative, although it was evident that she was quite blind. Herpetic ulceration of her lips and tongue were prominent features. There were tender patches of erythema on her elbow and foot.

The visual acuity was perception of light in each eye with accurate projection. Both eyes presented an identical picture of congestion, with lustreless corneae and large hypopyons with clumps of cells adhering to the back of the corneae above. The anterior chambers were cloudy and the pupils already fixed to the lens capsules. The tension * was normal in each eye and there was no pain, lid oedema, chemosis, proptosis, or restriction of ocular movements. No view of the more posterior structures was obtainable.

Diagnosis.-Septicaemia with complicating endophthalmitis.

\section{Laboratory Investigations}

Blood Count (on admission): Haemoglobin 60 per cent., W.B.C. 22,300 cu. mm., neutrophils 96 per cent., lymphocytes 3 per cent., monocytes 1 per cent., erythrocyte sedimentation rate $107 \mathrm{~mm} . / 1 \mathrm{hr}$ (Westergren).

Blood Culture: Of twelve bottles, three on three separate occasions grew $\beta$-haemolytic streptococci of Lancefield group A.

* Received for publication April 25, 1961. 
Anti-streptolysin Titre: 800 units/ml. (Normal up to $200 \mathrm{units} / \mathrm{ml}$.)

Blood Urea: $45 \mathrm{mg} . / 100 \mathrm{ml}$.

Other investigations including chest $x$-ray, urine analysis and culture, serum proteins, bilirubin, and electrolytes were normal; the Wassermann reaction and gonococcal complement-fixation test were negative.

Treatment.-Systemic steroids in large doses were instituted since the control of the ocular reaction was clearly of first importance. This was combined with local and systemic antibiotics.

Prednisone $100 \mathrm{mg}$. daily by mouth was abandoned in favour of $300 \mathrm{mg}$. hydrocortisone hemisuccinate daily by intramuscular injection, since the former appeared to have little effect. (Oral prednisone was re-instituted on discharge.) 8 megaunits penicillin were also given intramuscularly in divided doses.

Local treatment consisted of intensive atropine, Achromycin, and later hydrocortisone ointment. Subconjunctival Soframycin $250 \mathrm{mg}$. and mydricaine minims 5 were given to each eye on two occasions.

Course, Complications and their Management.-By the end of the first week, a general improvement was noted, the erythrocyte sedimentation rate had fallen to $75 \mathrm{~mm}$. $/ \mathrm{hr}$ and there was a slight reduction in the white cell count. The herpes of lips and tongue had increased and was causing some distress. The right eye showed no change, but the left cornea had brightened and the hypopyon decreased (Figs 1 and 2).

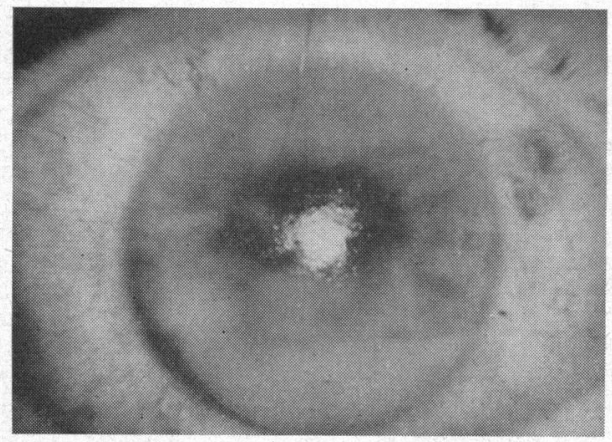

FIG. 1.-Right eye at the end of the first week, showing corneal oedema, hypopyon, and irregular fixed pupil.

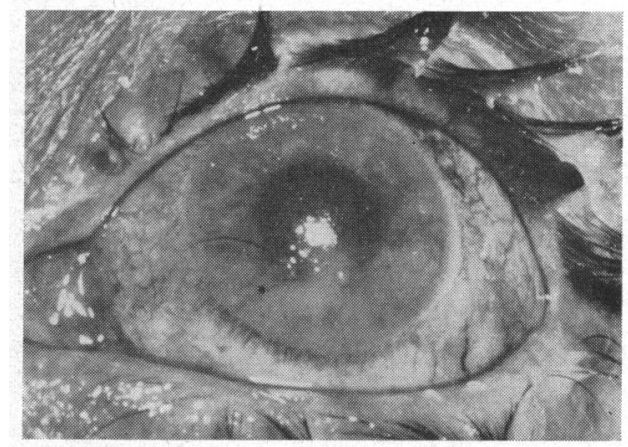

FIG. 2.-Left eye at the end of the first week, showing some corneal oedema and hypopyon contracting and absorbing.

By the end of the second week, the left hypopyon had gone and the right decreased, but a large corneal abrasion was present on the cornea of this eye.

By the middle of the third week, vision was still only projection of light, inaccurate in the left. There was a deterioration in the mental state and an increasing depression. The tension in the right eye was raised and the anterior chamber shallow. Cataractous changes in the lens were observed and lens swelling appeared to be responsible for the angle closure and the glaucoma. The left eye showed a yellowish white reflex in the vitreous.

Diamox and later Daranide were given with only temporary effect. Photophobia became intense, and 11 days later the eye was quite hard and the angle completely closed.

A right extracapsular extraction was therefore performed under general anaesthesia on November 25; the operation went very well, but post-operatively the cornea remained opaque and the anterior chamber became shallow again. 
Result.-At the time of the patient's discharge on December 30 (Figs 3 and 4), the right eye was unchanged, with accurate light projection only. The left anterior segment was almost normal but posterior cortical lens changes were present and the vitreous contained organizing exudate. The anti-streptolysin titre was still over 800 units $/ \mathrm{ml}$., and electroconvulsive treatment was necessary to alleviate the depression.

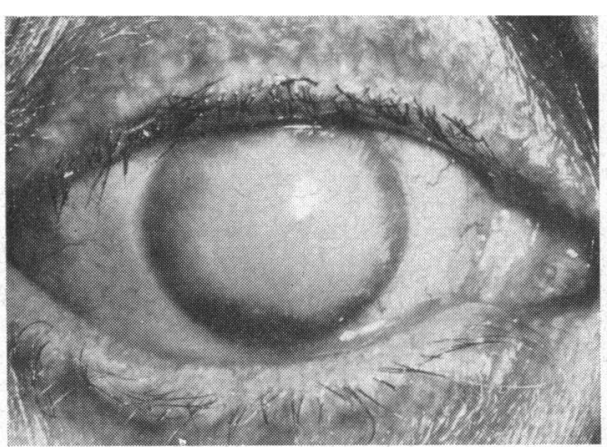

FIG. 3.-Right eye on discharge, 2 months after admission and one month after extracapsular extraction. The cornea is densely opaque, especially in its central portion, but it is bright and the tension is sub-normal. The anterior chamber is shallow and the visual acuity perception of light with accurate projection.

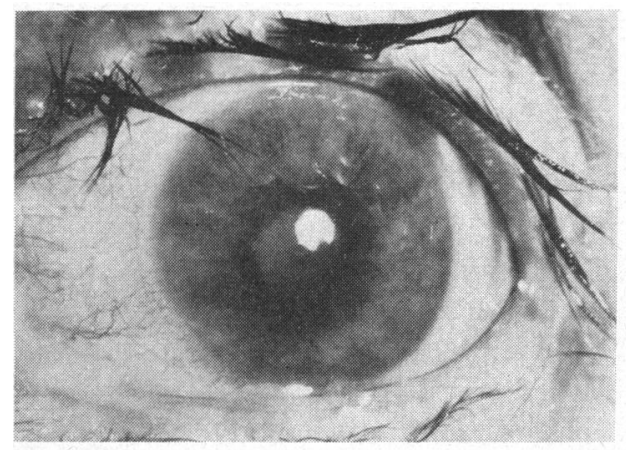

FIG. 4.-Left eye on discharge. The cornea is bright and the hypopyon resolved. The pupil is adherent to an apparently clear lens, but a yellowish-white reflex is visible behind it. The visual acuity is counting fingers at $1 \mathrm{~m}$.

\section{Discussion}

Clinical and experimental evidence is available showing that bacterial emboli may lodge in the eye in a wide variety of pyaemic and septicaemic states.

The organism most frequently found is the streptococcus (Duke-Elder, 1940). The precise mechanism of the reaction evoked (if there is one) is not always clear but several possibilities come to mind:

(i) That the ocular reaction is a toxic effect due to streptococcal toxin;

(ii) That bacterial invasion and multiplication within the eyes takes place, with local toxic effects;

(iii) That the uveal tissues may be particularly sensitive to streptococcal toxins and react excessively to it (tissue allergy);

(iv) That the above mechanisms are each contributory.

As regards the first, it seems likely that the whole family was infected with the same organism, yet only the patient suffered a severe illness. This suggests that there was something peculiar to the patient which led to such a severe illness, and not a purely toxic effect.

Also the ocular reaction occurred some 10 days after the first symptoms, which seems a long time for a purely toxic response to develop, and it was, in any case, out of proportion to the mildness of the general state. 
As regards bacterial multiplication in the eyes, this was incapable of proof, but pyaemic abcesses elsewhere were not in evidence and there was none of the ocular pain, chemosis, or proptosis with which one is familiar in cases of exogenous infection of the globes after intra-ocular operations, in which the presence of an infecting organism is subsequently readily proved.

A bilateral and virtually symmetrical incidence is not the rule in cases of bacterial metastasis; Axenfeld (1894) and Lewis (1936) found the majority of such infections to be unilateral.

It seems that the assumption of a uveal hypersensitivity satisfies most of the predominant features of the case. The occurrence of such a hypersensitivity to a wide variety of proteins and bacterial agents is well known, and latent periods between the first exposure to the antigen and the subsequent development of the excessive reaction are also familiar. Theodore and Lewson (1939) noted, in at least one case of serum sickness, that an active iritis occurred 10 days after the initial injection. The similar delay in the case of the patient here reported may be noted.

Woods (1960) noted that a severe antigen/antibody reaction may occur in the eye without any evidence of a general hypersensitivity, which seems to be illustrated in this case.

In conclusion, it may be of interest that the patient has recently been re-admitted to hospital for an attack of acute glaucoma in the left eye for which a peripheral iridectomy was performed. She developed a total hyphaema with blood-staining of the cornea and now has no perception of light.

\section{Summary}

A case of bilateral endophthalmitis in the course of a septicaemia is described.

The possible mechanism of the ocular involvement is discussed and the conclusion is drawn that a hypersensitivity reaction was the predominant cause.

We are indebted to Mr. John Winstanley for permission to publish this case and to the Photographic Department of St. Thomas's Hospital for the photographs.

\section{REFERENCES}

AXENFELD, T. (1894). v. Graefes Arch. Ophthal., 40, pt 4, p. 103. Duke-ELDER, S. (1940). "Text-book of Ophthalmology", vol. 3, pp. 2126-2195. Kimpton,
London.

LEwIS, P. M. (1936). Trans. Amer. ophthal. Soc., 34, 284.

TheOdore, F. H., and Lewson, A. C. (1939). Arch. Ophthal. (Chicago), 21, 828.

Woods, A. C. (1960). Amer. J. Ophthal., 50, 1170. 